\title{
The relationship between self-efficacy and instructional practice of in-service soft disciplines, hard disciplines and EFL teachers
}

\author{
Shabnam Kurosh Khanshan and Mohammad Hosssein Yousefi ${ }^{*}$
}

* Correspondence: mhh.yousefi@ gmail.com

English Language Department, Bonab Branch, Islamic Azad University, Bonab, Iran

\begin{abstract}
The present study aimed at investigating the relationship between teachers' selfefficacy perceptions and their instructional practices. The mediatory role of the teachers' occupational characteristics such as their disciplines was also examined. For this purpose, a total of 70 teachers from the soft science, hard science and English language teaching (ELT) disciplines were compared. This study was situated within a mixed-methods design in which questionnaires as well as observation and semistructured interviews were used to measure the efficacy-teaching practice. Results of Pearson correlation coefficients revealed that the self-efficacy of soft science and hard science teachers was significantly correlated with their teaching practice, with the ELT teachers' efficacy-teaching relation not reaching a statistical significance. Results obtained from the observation and interviews further explained the teachers' practices and the challenges that they faced in their classroom practices. Findings are discussed in light of both individual and societal perspective, offering important implications for the classrooms.
\end{abstract}

Keywords: Self-efficacy, Instructional practice, Discipline, Mixed-methods, Society

\section{Introduction}

Teacher efficacy is defined as teachers' belief in their ability to influence the learning of students, even those who could be regarded as difficult or unmotivated (Guskey \& Passaro, 1994). Gibson and Dembo (1984) identified two dimensions of teacher efficacy: internal efficacy (or personal teaching) and external efficacy (or general teaching). Internal efficacy represented teachers' belief in their skills and abilities to overcome difficulties students may have in their learning. On the other hand, external efficacy represented the belief that any teacher's skills and abilities to promote student learning were less powerful than external factors such as socio-economic status, family background, and parental influence.

Self-efficacy belief or self-efficacy has already turned into a significant realm in numerous fields, such as anthropology, applied linguistics, education and psychology (Kalaja \& Barcelos, 2003). Recently, teachers' self-efficacy beliefs in their instructional practice and learning have developed into a greater main issue for educational research

(c) The Author(s). 2020 Open Access This article is distributed under the terms of the Creative Commons Attribution 4.0 International License (http://creativecommons.org/licenses/by/4.0/), which permits unrestricted use, distribution, and reproduction in any medium, provided you give appropriate credit to the original author(s) and the source, provide a link to the Creative Commons license, and indicate if changes were made. 
(Fang, 1996) that attend to the teachers' expectations with respect to their capacity to impact learners as well as the beliefs about their own skills to carry out the specialized tasks that comprise teaching (Bandura, 1989). However, no sufficient research has investigated the relationship between different discipline teachers' self-efficacy perceptions and their instructional practices. The impact of discipline is significant since the rigor of the major, its prestige and place in the society, facilities for its development in universities, parents' perceptions and many other social and interpersonal skills influence teachers' teaching practice. In addition, it has been depicted that different discipline teachers can go through distinct occupational challenges, different societal expectations, specific work environment conditions, and individual characteristics (Lawson, Çakmak, Gunduz, \& Busher, 2015; Wilson, 2012). Wilson (2012) maintains that the individuals with particular types of personalities, intelligences, skills, capacities and aptitudes are likely to differ with regard to their choice of disciplines. For instance, because of their very nature, hard science disciplines might be interesting for individuals who tend to be more imaginative, curious, adaptable, and novelty seeking, while more conservative, conventional, down-to-earth, and practical individuals are likely to opt for a teaching career in soft sciences. Consequently, these different characteristics and specificities are expected to be influential upon teachers' self-efficacy and their instructional practice, which have not been investigated as of yet. As a result, the present study intended to fill these gaps in the teacher development literature by providing answers to the ambiguities in the field.

\section{Review of the literature}

Self-efficacy in a teaching context refers to the teachers' realization of their own capabilities and skills to bring about changes in learners' achievement in positive ways (Tschannen-Moran, Woolfolk-Hoy, \& Hoy, 1998). It has been characterized as a crucial specificity of teachers who can positively impact both the student outcomes and the other teachers. Bandura, who is famous for his seminal studies and proposals on numerous types of efficacy, recommends that "the task of establishing learning environments conducive to the development of cognitive competencies in students relies heavily upon the talents and self-efficacy beliefs of teachers" (Bandura, 1997, p. 240).

The results of studies indicate that deliberately employing acts of teaching to improve individuals with struggling self-efficacy are essential. Pritchard and Honeycutt (2007) suggest that "skills and emotions are intertwined, and therefore some of the stress that fosters negative attitudes is reduced when individuals are provided adequate instruction" (p. 31). In addition to deliberate teaching, observing others succeed through their efforts, which includes observing peers' efforts resulting in achievement and a practitioner modeling the target strategies, has the potential to improve self-efficacy (Bandura, 1977).

Schunk (1991) found that individuals "exposed to models displayed higher motivation during instruction than did those who did not observe a model" (p. 216). Schunk and Meece (2006) suggest that the greatest effects are evident when the models are those "whom individuals believe are similar to themselves" (p. 88). However, there is a possibility that the struggling individuals' observation of others' failures may lower their efficacy and discourage them from trying. Encouraging struggling individuals verbally and 
praising their efforts and achievement may also have a positive effect on their selfefficacy, but the positive influence of verbal assurance (persuasion) that they have the ability to achieve will only last with subsequent performance (Bandura, 1977).

In sum, it can be argued from the results of the existent literature that because the individuals themselves, be it learners or teachers, are the highest variant in their achievement, teachers need to assess and attend to the negative emotions in themselves and the learners and create "a positive, nonthreatening social climate in which they learn frequently" (Pritchard \& Honeycutt, 2007, p. 31). In positive writing environments, teachers deliberately build positive relationships with their students (Graham, MaCarthur, \& Fitzgerald, 2007). Bishop and Berryman (2009) found that "relationships and interactions between teachers and students in the classroom are key to effective teaching of students" (p. 27). Therefore, it can be put forward that the teachers' classroom practices arise and become strengthened and reinforced through effective reflective practice; that is, the relationship is dialectical (Richards, 2008). As a result, examining the teachers' self-efficacy perceptions is usually associated with identifying the extent to which they are capable of critically reflecting on their performance and how they believe this can affect their pedagogical practices. Even though there is a large body of the literature documenting research findings in each of these areas separately, our knowledge concerning the teachers' conceptualization of teaching and the ways that their thinking is related to their classroom practices is still limited. More importantly, no attempt has been made so far to explore these relationships for teachers from different academic disciplines. The present study was therefore an attempt to examine the relationship between these significant contexts among soft science, hard science and English as a foreign language (EFL) teachers in the Iranian context.

Teaching self-efficacy has been found to be positively related to numerous professional development practices (Noe \& Wilk, 1993) and work-related learning (Deci \& Ryan, 1985). It needs to be noted that teacher efficacy influences the teachers' teaching processes and their reasons behind their decisions in their real classroom teaching settings. Teachers' views about their efficacy give the signal that what type of practices they implement, including activities related to class planning, decision-making and post-class reflection (Caprara et al., 2008, 2011). As a result, teachers' efficacy beliefs refer to and reinforce their classroom practices (Richards, 2008).

\section{Instructional practice}

Considering the growing number of English language learners over the past decades in different parts of the world and the status of English as a lingua franca, the use of effective instructional practices in the classroom has been into the spotlight (Hemphill, Vanneman, \& Rahman, 2011; O'Conner, Abedi, \& Tung, 2012; Pandya, Batalova, \& McHugh, 2011). Researchers have indicated that instructional practices that emphasize the constructivist approach to learning, such as differentiated instruction (Brooks \& Thurston, 2010; Kanevsky, 2011; Reis, McCoach, Little, Muller, \& Kaniskan, 2011; VanTassel-Baska, 2012) and Vygotsky's (1978) zone of proximal development (ZPD; Kanevsky, 2011; Lantolf \& Poehner, 2010) would enhance learners' achievement, consisting of English or non-English learners. These approaches entail, but are not restricted to, activities according to individual learner differences, small group or pair- 
work activities, hands-on and technology-supported tasks, and inquiry-based learning (Baecher, Artigliere, Patterson, \& Spatzer, 2012; Brooks \& Thurston, 2010; Burnett, 2010). A lot of these approaches are practiced in classrooms routinely and commonly; nonetheless, integrating these practices into every day teaching might pose challenges for the teachers. The essence of the attention to these approaches can lead to significant differences with respect to the learners' learning process and their accomplishment.

Studies have highlighted the role of differentiation in the instructional practices of the teachers in their classroom contexts. Particularly, Baecher, Rorimer, and Smith (2012) reported 10 principles for effective instructional practices based on the tenets of differentiated instruction that they believe need to direct the teachers in their instructional practices. In addition to emphasizing the principles, the amount of time that is actually devoted to differentiation is also crucial to note (Azano et al., 2011). There is evidence that teachers who use differentiated instruction based on their learners' needs enable their learners to attain educational gains (Kanevsky, 2011; Lantolf \& Poehner, 2010; Okoye-Johnson, 2011; Orosco \& O'Connor, 2014). NevJrez-La Torre (2011) considers the implementation of research supported instructional practices, such as humanistic approaches to learning. Hence, differentiating instruction by means of using a number of practices would be of value, particularly to the learners. One way of differentiating instruction is through the degree of support a teacher provides learners, namely the zone of proximal development. In this well-known practice, the teacher attempts to help the learners discover the learning objectives and scaffolds their discovery learning through providing feedback or clarification when needed.

Another factor that is presumed to be conducive to the instructional practice of the teachers in the classroom is the expectancy of teachers in the learning skills and capacities of their learners. When a teacher's expectation of learner performance is not very high, then they tend to employ the objectives of the established curriculum in lower than common levels (Azano et al., 2011). Teacher's belief about their own specialty and degree of knowledge (Azano et al., 2011) can also impact the instructional practice. Expertise can be evaluated based on the instructional readiness. Instructional readiness is influenced by the teaching experience of the teacher, how much professional development a teacher has gained, teacher certification, and teacher readiness. Quality of teaching is not only impacted by teachers' beliefs in their learners' skills to learn but also in their beliefs about their own capacities to perform the lessons. Teachers' feelings of incompetence and ineffectiveness to carry out their job could impact their learners' eagerness to learn.

It is clear that although the concept of instructional practice has gained considerable attention in the literature, there have been very few systematic studies to investigate the relationship between reflection, teacher self-efficacy and the instructional practice. Runhaar, Sanders, and Yang (2010), for example, explored how teachers' reflection and feedback could be related to occupational self-efficacy, learning goal orientation and transformational leadership. A survey study with 456 teachers from a Dutch College revealed that occupational self-efficacy and learning goal orientation were positively related to reflection and feedback asking. In addition, learning goal orientation mediated the relationships between occupational self-efficacy and reflection and asking feedback. Lastly, the positive relationship between transformational leadership and reflection and asking feedback were found to be reliant upon learning goal orientation. 


\section{Method}

The present study, in line with the significance of the abovementioned issues, aims at investigating the relationship between teachers' self-efficacy and their instructional practices. These relationships, however, are also mediated by the teachers' occupational characteristics such as their disciplines. Thus, in order to better clarify this issue and to explain how different disciplines might differentially affect efficacy beliefs and teaching practice, the soft science, hard science and ELT teachers were compared. The study adopted a mixed-methods design to obtain an in depth understanding of how selfefficacy perceptions could impact different discipline teachers' instructional practices through the use of both questionnaires and observations. More, particularly, the following research questions guided the present study:

1. Is there any significant relationship between Iranian soft discipline, hard discipline and ELT in-service teachers' self-efficacy (SE) and instructional practice (IP)?

2. How do Iranian soft discipline, hard discipline and ELT in-service teachers reflect on their instructional practices (IP)?

\section{Participants}

A total of 70 university teachers from different departments of public and private universities throughout Iran (physics $=10$, chemistry $=10$, mathematics $=10$, law $=10$, economics $=10$, psychology $=10$, and English language teaching $=10)$ took part in the present study. Participants included 37 males and 33 females and their age ranged from 27 to $64(\mathrm{M}=40.25, \mathrm{SD}=7.61)$. All of the participants were randomly chosen from distinct universities based on their availability to the researcher and for being helpful to the objectives of this study. Participants were as a result from a large number of universities consisting of both state and private settings. The teachers were chosen on a voluntary basis and were ascertained about their anonymity by withholding their real names from all stages in the current research study. Teachers' teaching experience and level of education were controlled by including only those participants with over 10 years of experience $(\mathrm{M}=22.54,6.94)$ and those who were mainly $\mathrm{PhD}$ holders $(N=58)$ with the rest of the teachers holding MA $(N=12)$. In addition, the other individual variables such as marital status were not controlled.

\section{Instruments}

Teacher efficacy scale (TES)

The Teacher Efficacy Scale (TES) (Gibson \& Dembo, 1984) was implemented in order to gather quantitative data with respect to the teachers' general and personal selfefficacy. This survey is a widely used quantitative instrument in the realm of teacher development. Personal self-efficacy refers to the extent to which teachers' perspectives and opinions regarding their teaching abilities help them deal with the challenging learners from less supportive contexts to reach elevated and appropriate academic results. The general efficacy, in contrast, alludes to the teachers' beliefs regarding their teaching ability to work against the unconstructive and undesired effects on learners' background. 
The current form of the questionnaire is a 16-item form of Gibson and Dembo's Teacher Efficacy Scale (1984) which is decreased from 30 original items due to the fact that they could attain an appropriate reliability index of 0.79 employing just 16 items. Furthermore, the use of a principal component factor analysis on the original questionnaire led to the production of a 16-item scale that comprised two major sections of personal teacher efficacy (PTE $=9$ items) and general teacher efficacy (GTE $=7$ items). Nevertheless, in order to establish the psychometric properties of the instrument in the current study, a pilot study with 7 teachers, one from each discipline, was conducted. The items of TES were measured on a six-point Likert-type scale from strongly disagree (1) to strongly agree (6).

\section{Instructional practices survey}

A Likert-scale questionnaire named the Instructional Practices Survey was adopted from Hong, Greene, and Higgins (2006) in order to tap into the teachers' instructional practices for language learners. The questionnaire consists of the instructional activities that would be constructive in terms of developing the essential skills in the cognitive, interpersonal, and intrapersonal domains.

\section{Observation}

Teachers' classroom instructional activities were observed in order to note their pedagogical choices and to see whether these were impacted by particular beliefs and idiosyncratic inclinations. The observation checklist was taken from Richards (2011) which encompasses the most essential features of a classroom practice such as teaching the targeted skills, activities, teacher behavior, question and answer, feedback, learner engagement, motivation and so forth. This checklist pursues the goal of entailing most of the teaching dimensions in the classroom by addressing the cognitive, interpersonal and intrapersonal dimensions of teaching. Because of its comprehensibility and completeness, this checklist was also used in the current study.

\section{Semi-structured interview}

Interviews are a popular method of data collection as they provide an explanation as to why people act and think in particular ways (Menter, Elliot, Hulme, Lewin, \& Lowden, 2011). In this research, interviews were used to help interpret and elaborate on the thoughts, opinions and ideas of the participants that were revealed during their classroom teaching practices. The interviews were also intended to uncover beliefs as well as differences between participant's espoused theory and theory in use (Robinson \& Lai, 2006).

Merriam (1998) stated that interviews require a skilled interviewer that is "nonjudgmental, sensitive, and respectful of the respondent" (p. 109). While this can be interpreted as strength for interview study research, it can be a possible limitation of this method. Cohen, Manion, and Morrison (2011) discuss the importance of developing a rapport with the participants before the interview commences. They suggest that doing this provides a relaxed environment which allows participants to give authentic responses (Cohen et al., 2011). In order to be able to ensure the success of the interviews in this research, the interviewer was mindful of developing the essential rapport 
with all of the participants in all majors while working within each data collection context.

Interviews in the current study were in fact aimed at providing a more "in-depth investigation of people's attitudes and experience" (Robinson \& Lai, 2006, p. 88). The interviews were semi-structured (McNeill \& Chapman, 2005; Sarantakos, 2005) with a number of questions prepared by the researcher beforehand. Teachers were asked numerous questions related to their teaching activities and why they selected those activities and instructional practices. The whole interview for each teacher took about $20 \mathrm{~min}$ on the whole. Teachers' responses were written on papers by the researcher. The interview questions were piloted with the same 7 teachers as well.

\section{Design}

The data in this study were collected through questionnaires, interview and observation making this study a mixed-methods research. The debate concerning the employment of a mixed method approach that encompasses the use of both quantitative and qualitative data (as opposed to using only quantitative data, or only qualitative data) in research has become a hot issue in recent decades. Creswell (2009), for instance, views mixed method research as one that is based upon the positive points of both quantitative and qualitative data, with the strengths of one approach compensating for the negative dimensions of the other and the other way round. For example, the meticulousness and reliability of quantitative data offered by eminent, standardized tests redressed the balance regarding the challenges in employing the standards of reliability to qualitative data. In similar ways, qualitative data manifests the components of human behavior, a feature that is not adequately captured through the use of quantitative methods (Burns, 2000). Morse and Neihaus (2009) suggest that mixed method design be implemented when one method used singularly would not be able to target the research question in a comprehensive way. Gorand and Taylor (2004) point out, "no one method is intrinsically superior to any other" and the combination of the traditional qualitative and quantitative approach is "powerful in practice" (p. 176). Halvorsen, Lee, and Andrade (2009) contend that merging the qualitative and quantitative research agendas is not a secluded and confrontational matter; rather, it is "complementary, integrative and conciliatory" (p.188).

\section{Procedures}

Before conduction of the main study, a total of 7 teachers from all disciplines served as the pilot sample whose responses determined the psychometric properties of the questionnaire and interview. These pilot teachers had the characteristics similar to those of the main study. It also needs to be mentioned that the data obtained from pilot teachers was only used for the purpose of reliability and validity indexes. Afterwards, for the main study, the teachers were first observed during their classroom teaching in order to better cover their use of pedagogical activities. Afterwards, the same teachers were interviewed in order to obtain insights about the teachers' classroom practices. Lastly, they were given the efficacy and instructional practice questionnaires to either complete on the research site or complete it at home and return it to the researcher via email. 
Intercoder reliability otherwise known as inter-rater agreement was used (Corbin \& Strauss, 2008). The researcher selected two peer researchers who used the coding labels that were identified by the researcher to code several pages of the transcribed interviews. The transcripts were randomly selected and those sections, phrases or words that had previously been coded by the researcher were highlighted though not defined. After the peer researchers had completed coding the transcript, it was then compared to the transcript that the researcher had coded allowing for the calculation of intercoder reliability. This was an iterative process whereby modifications were made to the framework until a $90 \%$ agreement was reached. The inter-rater reliability of the raters' evaluation of the observation and interview codes was computed using Cohen's Kappa test. The resulting Kappa of .98 for the observation and .96 for the interviews indicates that both raters provided similar information about the results regarding teachers' instructional practice and their opinions towards it. In addition, the reliability of TES and the Instructional Practices Survey was estimated through Cronbach's Alpha. The resulting alpha of .69 for TES and .89 for the Instructional Practices Survey indicate that these questionnaires have all achieved a satisfying and appropriate level of consistency.

After the collection of the returned and complete questionnaires, the scores were calculated and entered into the statistical package for the social sciences (SPSS) software for the quantitative data analysis. First, the normality of the data and other presumptions of correlation analysis were determined. Afterwards, in order to provide answers to the research questions, a series of correlation analyses were run. For all analyses, a significance level of .05 was set. Effects sizes were analyzed according to Cohen (1988): $\eta p 2$ values of .01, .06, and .14 and $d$ values of $.20, .50$, and .80 were considered small, medium, and large.

With respect to the analysis of observation, the obtained themes from the teachers' classroom teaching were coded and categorized based on interpretive content analysis.

\section{Results}

In order to find out whether there was any relationship between the participants' selfefficacy and instructional practice, a Pearson correlation coefficient was performed. Results are presented in Tables 1 and 2 .

The results of Table 1 indicate that there is a moderate, positive, and significant correlation ( $\mathrm{r}=0.46, p=0.000)$ between the participants' self-efficacy perceptions and their instructional practice on the whole.

In order to provide an answer to the eights research question concerned with the ELT teachers' self-efficacy perceptions and instructional practice, a Pearson correlation coefficient was carried out. Tables 3 and 4 report the results of Pearson correlation coefficient for the relationship between ELT in-service teachers' practice teaching and self-efficacy.

Table 1 Descriptive Statistics for Self-efficacy and Instructional Practice

\begin{tabular}{llll}
\hline & Mean & Std. Deviation & $\mathrm{N}$ \\
\hline Efficacy & 71.1143 & 7.95193 & 70 \\
Practice & 34.2000 & 6.76221 & 70 \\
\hline
\end{tabular}


Table 2 Pearson Correlation Results for Self-efficacy and Instructional Practice

\begin{tabular}{llll}
\hline & & Efficacy & Practice \\
\hline Efficacy & Pearson Correlation & 1 & $.461^{\text {a }}$ \\
& Sig. (2-tailed) & & .000 \\
& $\mathrm{~N}$ & 70 & 70 \\
Practice & Pearson Correlation & $.461^{\mathrm{b}}$ & 1 \\
& Sig. (2-tailed) & .000 & 70 \\
& $\mathrm{~N}$ & 70 & 70 \\
\hline
\end{tabular}

${ }^{\mathrm{a}}$ Correlation is significant at the 0.01 level (2-tailed)

The results of Table 4 refer to a non-significant correlation $(p=0.50)$ between the ELT participants' instructional practice and their self-efficacy perceptions.

Tables 5 and 6 report the results of Pearson correlation coefficient for the relationship between soft discipline in-service teachers' instructional practice and self-efficacy.

As Table 6 demonstrates, there is a moderate, positive, and significant correlation $(\mathrm{r}=0.54, p=0.002)$ between the soft discipline teachers' self-efficacy perceptions and their instructional practice.

Lastly, Tables 7 and 8 report the results of Pearson correlation coefficient for the relationship between hard discipline in-service teachers' self-efficacy perceptions and their instructional practice.

The results obtained from Table 8 refer to a moderate, positive, and significant correlation $(r=0.41, p=0.02)$ between the hard discipline teachers' self-efficacy perceptions and their instructional practice.

\section{Interview results}

The teachers' responses to the interview questions were analyzed using interpretive content analysis. The responses and the interpretation of the teachers' ideas and attitudes are presented in a step-by-step fashion through each interview question.

The first interview question asked whether the teachers monitored students' progress in order to select, improve or change your instruction. Teachers' responses made it clear that almost all of the teachers in all scientific fields remarked that they in fact monitored learners' development. For instance a physics teacher declared that:

Yes, sure. Our learners' progress being monitored constantly in educational situations, through the steady stream of homework assignments, quizzes, tests, projects and standardized tests. Our initial reaction may be "they're doing this already" or more tests? So, progress monitoring can give you and your learners information that can help your learners learn more and faster, and help teachers teach more effectively and make better decisions about the type of

Table 3 Descriptive Statistics for ELT Teachers' Self-efficacy and Instructional Practice

\begin{tabular}{llll}
\hline & Mean & Std. Deviation & $\mathrm{N}$ \\
\hline efficacy & 72.0000 & 8.53750 & 10 \\
practice & 32.5000 & 5.38000 & 10 \\
\hline
\end{tabular}


Table 4 Pearson Correlation Results for ELT Teachers' Self-efficacy and Instructional Practice

\begin{tabular}{llll}
\hline & & Efficacy & Practice \\
\hline Efficacy & Pearson Correlation & 1 & .239 \\
& Sig. (2-tailed) & & .505 \\
& $\mathrm{~N}$ & 10 & 10 \\
Practice & Pearson Correlation & .239 & 1 \\
& Sig. (2-tailed) & .505 & \\
& $\mathrm{~N}$ & 10 & 10 \\
\hline
\end{tabular}

instruction that will work best with your learner. It is a way of helping the learner learn and the teachers teach. So, it's not just a way of assigning a number to your learner.

Another teacher from chemistry discipline stated that "Yes, I use tests on a regular basis in order to measure students' progress. If the scores of the learners increase comparing previous weeks or sessions so, the teaching methods and instruction were effective. Otherwise I try to revise my teaching methods". Teachers on the whole from the hard science group sated that they closely monitored students and instruct accordingly.

Teachers from the soft science discipline as well indicated their positive responses to this question. For instance one law teacher maintained that "every session before starting the new lesson, I require them to talk about the key parts of the lesson and what they learned the previous sessions. Actually most of the sessions I ask them to give a summery about what they have learned". A psychology teacher confirmed these points by stating that "through the regular holding of tests, projects and different types of inquiries I try to monitor students' progress and if the used techniques did not work well I will do my best to change instruction method in order to improve the learning and help learners to learn faster which will help me to make better decisions about the type of instruction". Two teachers from economics discipline emphasized the importance of learners' progress but also underlined the restrictions imposed by the syllabus and other issues: "It depends on the task, also the number of the students in that class. In some cases it is near to impossible to do so, due to the available restrictions in time and freedom of the instructor". Another teacher from economics went on to say that "Yes, if the syllabus lets".

An ELT teacher also corroborated other teachers' opinions by adding that "Yes surely. As a teacher we know that monitoring student learning in the classroom helps us to make better instructional decisions that help students' progress. So, based on my course plan I use tests or frequent evaluations in order to monitor their progress and put grade for every student on each question. If I feel there is a problem I will re-teach the necessary parts". But, as mentioned above, there were some challenges considered by teachers as obstacles to the monitoring process and as such the alteration in the classroom teaching. For instance one ELT teacher noted that "most of the time I try to

Table 5 Descriptive Statistics for Soft Discipline Teachers' Self-efficacy and Instructional Practice

\begin{tabular}{llll}
\hline & Mean & Std. Deviation & $\mathrm{N}$ \\
\hline Efficacy & 73.4667 & 7.23847 & 30 \\
Practice & 35.8667 & 6.25732 & 30 \\
\hline
\end{tabular}


Table 6 Pearson Correlation Results for Soft Discipline Teachers' Self-efficacy and Instructional Practice

\begin{tabular}{llll}
\hline & & Efficacy & Practice \\
\hline Efficacy & Pearson Correlation & 1 & $.544^{\mathrm{a}}$ \\
& Sig. (2-tailed) & & .002 \\
& $\mathrm{~N}$ & 30 & 30 \\
Practice & Pearson Correlation & $.544^{\mathrm{b}}$ & 1 \\
& Sig. (2-tailed) & .002 & 30
\end{tabular}

${ }^{a}$ Correlation is significant at the 0.01 level (2-tailed)

monitor learners' progress as much as possible, but in crowded classes or in other words in classrooms which the number of students is more, one by one monitoring is to some extent impossible".

The second interview question probed into whether the teachers attempted to use innovative teaching ideas in their classroom or they thought that they have to strictly follow the syllabus. Responses varied for this question. The majority of ELT teachers conceded that the use of technology in the language classroom greatly impacts the learners' language learning. For example, one ELT teacher noted: “Teaching materials, teaching techniques should be updated to the interest of the second language learners. Innovative methodologies like use of games, role play, reading newspaper, watching TV, referring to dictionary etc.; should be used as tools in the classroom. Skill based learning, knowledge based learning are essential for the growth and development of students". Another teacher stressed that "Since I do not agree with a strict syllabus during a course so I try to use innovative teaching ideas in my classroom. Most of the times, I use questioning (Inquiry-based learning). I ask them to ask questions (develop some questions regarding the topic) and then in different groups try to answer their own questions. In fact, they do research on the topic which has been taught. I think this method helps learners to have a deeper understanding of the topic and also learn in a friendly situation". Other responses from the teachers in the ELT group conformed to this idea while there were some teachers that believed in spite of their interest in the use of innovative teaching, class size, facilities, syllabus and other factors slowed them down from adopting the innovative methods.

Teachers from the soft discipline posed different ideas regarding this question. It can be said that almost half of the teachers agreed and the other half disagreed with the use of innovative methods. For instance, one economics teacher asserted that "Yes, I have my own teaching method and I teach beyond the required and established syllabus. I make use of innovative teaching ideas". Another teacher from law discipline maintained that he attempted to raise questions on his own mind by evaluating the context of his class. In other words, he wanted to see if learners were ready to the use of new methods and whether their level allowed him to adopt these, then he in fact

Table 7 Descriptive Statistics for Hard Discipline Teachers' Self-efficacy and Instructional Practice

\begin{tabular}{llll}
\hline & Mean & Std. Deviation & N \\
\hline Efficacy & 68.4667 & 7.88597 & 30 \\
Practice & 33.1000 & 7.45261 & 30 \\
\hline
\end{tabular}


Table 8 Pearson Correlation Results for Hard Discipline Teachers' Self-efficacy and Instructional Practice

\begin{tabular}{llll}
\hline & & Efficacy & Practice \\
\hline Efficacy & Pearson Correlation & 1 & $.415^{\text {a }}$ \\
& Sig. (2-tailed) & & .023 \\
& $\mathrm{~N}$ & 30 & 30 \\
Practice & Pearson Correlation & $.415^{\text {a }}$ & 1 \\
& Sig. (2-tailed) & .023 & \\
& $\mathrm{~N}$ & 30 & 30 \\
\hline
\end{tabular}

${ }^{a}$ Correlation is significant at the 0.05 level (2-tailed)

implemented innovation. One teacher, however, from the psychology major said that she would use "the latter one, since it is not a good idea to test something without any previous positive feedback".

Teachers from the hard discipline stated that they mostly used a mixture of both traditional and innovative approaches in their classes. A chemistry teacher said that "I use both of them. Teaching is always contextual. But it is hard to depend on a syllabus. So, I start with the syllabus, using activities of the course, specific objectives and also specific ways of assessing learners. So, the syllabus is the guide for the activities. Then by innovative ways I move to other parts of the course". Another chemistry teacher contended that she "use every new technique which I think will be effective in the classroom". Interestingly, responses varied from "being innovative while using the syllabus", "a mixture of both. The syllabus should be followed in general because it is necessary to cover all the topics but some other techniques such as doing discussions can also take place" to the "use of innovative teaching ideas".

Teachers' answers to the third question about the role of learners' needs were mostly positive. The majority of ELT teachers replied that they considered needs analysis an important part of their teaching. An ELT teacher answered: "we should take into consideration those factors related to needs analysis and make sure that the demanding job of teaching will work for it. Therefore, teaching is dependent upon what you do with your learners". Another ELT teacher said that "since in academic module the instructor needs to make some decisions based upon the needs analysis done from the students, and follow an active teaching method based on the taken feedback". The soft science teachers were also careful about the learners' needs: "Yes, needs analysis is the most important technique". A law teacher declared that "Yes, they constitute major part of my teaching practice". Another teacher from the psychology camp asserted that "Teaching process should be based on needs analysis which is a systemic process that helps teachers to get a complete picture of their students' needs and preferences. So, it helps a teacher to elucidate the purpose of his/her learning program". In line with these opinions, hard science teachers also considered needs analysis important. A chemistry teacher said that "it is an important and basic part of every classroom". other opinions were: "Yes students' needs are my first concern", "Since mainly I follow the syllabus so I think the syllabus designers should consider learners needs analysis and by exact follow, their needs will be considered and the learning problems will be resolved", and "Yes, surely, Because as an instructor I need to make some decisions regarding students' needs" and other similar opinions. 
The forth question asked about the use of learner-friendly activities (e. g; group work, free discussions, role plays, meaningful tasks and so forth) to make your students motivated in the content being shared. An ELT teacher provided a comprehensive answer:

Yes, students who are not motivated will not learn effectively. They won't retain information, they won't participate and some of them may even become disruptive. A student may be unmotivated for a variety of reasons: they may fell that they have no interest in the subject, find the teachers methods un-engaging or be distracted by external forces. It may even come to light that a student who appeared unmotivated actually has difficulty learning and is need of special attention. Ask students to work in pairs or in groups. Get them out of their seats and moving. Ask them to change partners regularly. To keep your students attention, set a variety of engaging meaningful activities and create a friendly atmosphere where they feel they can talk freely and ask questions. While motivating students can be a difficult task, the rewards are more than worth it. Motivated students are more excited to learn and participate. Simply put: teaching a class full of motivated students is enjoyable for teacher and student alike. Some students are self-motivated with a natural love of learning. But even with the students who do not have this natural drive, a great teacher can make learning fun and inspire them to reach their full potential.

Another ELT teacher stated "Not often, but in some cases it is a must to make a warm up, and get the learners involved in the shared topic". One other ELT teacher noted that "motivation is one of the requirements in every classroom which results in effective learning. So, in order to motivate the learners I should believe in them and encourage to do the activities or to solve the problems successfully. And the key to this technique is group work. During solving the problem I try to walk in the class and have a one to one deal with all of them. I think this technique is so helpful because when learners completely can solve a problem and see their success they will enjoy the learning". In a similar way, soft science teachers stated their positive opinions regarding the use of learner-friendly activities. A psychology teacher stated that "Yes, team work and discussion are fundamentals of effective teaching because based on my experience these factors work well". Others from the lay, economics and psychology fields respectively mentioned: "The atmosphere of my class is a mixture of friendly learning and seriousness", "Yes, learner friendly activities like group work", "using these kinds of activities may create a positive learning environment and this in turn may affect student achievement. As a teacher we should know that learners have not only physical needs but also some important psychological needs for feeling secure, belonging, competence, freedom and fun. So, when teachers intentionally address these needs in their classrooms, students are happier to be there and in result student engagement and achievement increases".

Teachers from the hard science field noted that they were inclined towards the use of learner-friendly activities. One math teacher declared that "I use suitable learner friendly activities such as discussion or meaningful tasks which are discussed or solved in groups or as pairs". Another math teacher continued "Yes, all the time. Because a class without those activities will be a rigid environment which will demotivate the 
learners and will be a monotonous and boring class which students won't like to attend". A physics teacher stated that "In the previous year of teaching I used collaborative learning techniques such as group-work or putting the students into different groups and asking them to discuss a topic and give the result of discussion to the whole class but recently I try to use both a mixture of these techniques accompanied with technological tools. Because students are interested in technology and it will engage them". Lastly, a few teachers from the math field disagreed with the use of learnerfriendly activities:

Not all the time but as it is necessary. Because learner-friendly activities make a positive environment for learners where there is not just serious teaching but interactive condition. But most of the time in order to teach all the topics mentioned in the syllabus there is not enough time to other activities.

The last interview question asked about the use of established syllabus purposes or the development of an engaging and meaningful learning environment for learners. Similar to the previous questions, the responses for this question varied among teachers. Although the majority of teachers welcomed the use of motivating and authentic activities in the classroom, some raised concerns about the efficacy of these activities with respect to the limitations imposed to the classroom.

An ELT teacher held positive attitude by saying that:

"Students look to teachers for approval and positive reinforcement and are more likely to be enthusiastic about learning if they feel their work is recognized and valued. You should encourage open communication and free thinking with your students to make them feel important. Be enthusiastic. Praise your students often. Recognize them for their contributions. If your classroom is a friendly place where students feel heard and respected, they will be more eager to learn. A "good job" or "nice work" can go a long way. In teaching it is important to know how learners learn. If we teach in a connected and related way most of them will learn properly. Otherwise learning difficulties may arise. Essential principles to do meaningful learning are detailed below: 1. Open work enables all learners to learn. 2. Motivation helps to improve classroom environment and it makes learners be interested in their tasks. 3. Means must be related to the environment of learners. 4. Creativity strengthens imagination and intelligence. 5 . Concept mapping helps learners to link and connect concepts. 6 . Educational curricula must be adapted considering learners with special needs.

However, an ELT teacher was not sure about the use of different meaningful activities: "The former one, since being loyal to the syllabus given may guarantee the full coverage of preplanned teaching materials. Besides, the answer to this question might be different in various contexts". Others agreed that it is important to create an engaging and meaningful learning environment "because in this case there are more opportunities for practice and growth, because they can link the classroom activities to their own real-life experiences".

Teachers in the soft and hard science discipline also provided similar responses; they favored both types. A chemistry teacher answered "I mostly try to have creativity in my 
teaching and at the same time have meaningful learning atmosphere". On the other hand, another chemistry teacher emphasized that "Since I strictly follow the syllabus so covering the contents and purposes of syllabus is more important". A math teacher believed that 'Since positive and productive learning environments are key to students' academic, emotional and social success so creating positive, engaging and meaningful learning environments for learners is preferred. In fact, when the students view the class as relevant to themselves and their interests they pay more attention and are more excited about the course". A physics teacher stated that "Both of them. Mostly established syllabus must be covered and where it is necessary I try to engage the students". Lastly, the soft science teachers provide similar opinions by stating that "It's ideal to cover both of them" (law teacher), "Creating meaningful learning environment to engage students is preferred" (law teacher), "Since I do not follow the syllabus I think creating an engaging and meaningful learning environment is more important than strictly covering the syllabus" (psychology teacher), "Creating an engaging and meaningful learning environment works well. Because by making meaningful atmosphere in fact you give the learners the opportunity to relevant the classroom activities to their own real life experiences and get them more involved in learning and also allow them to more reflect on the topic" (economics teacher).

\section{Observation analysis}

In order to better understand whether the teachers in reality used the abovementioned ideas in their classroom practice, an observation procedure was taken. The results of it are presented in this section.

Regarding the 'preparation' features that were observed in the classes, it was found that the majority of teachers could come up with clear objectives of what they wanted to teach in the class, had specific objectives for the lesson, and could choose appropriate materials according to the objectives, had an efficient time planning based on the objectives. However, it was observed that since the classes in almost all disciplines were very crowded, the teachers encountered problems in management of time for the activities and the adjustment of the lesson plan based on the learners' level.

Concerning the 'teaching' aspect of the observation checklist, it was observed that the use of meaningful communication was limited mostly in the hard science fields. In addition, teachers particularly ELT teachers did not provide feedback to their learners, nor did they evaluate whether their learners were involved in the activities. The soft science teachers were also observed to deviate from the teaching routine that was not consistent with the evaluation or instruction objectives.

Teachers' performance was well on the 'management' dimension of the observation checklist. Most ELT teachers attempted to group learners based on the activities and had effective time management and could deal with unexpected classroom problems. Other teachers from the soft and hard disciplines were also efficient in terms of these aspects of their teaching.

The 'self-management' aspect of the observation concerned with the teachers' punctuality, friendly and respectful attitude towards learners and the use of body language. Although the majority of teachers from all the three majors attempted to establish 
these behaviors with the learners, some teachers were serious, not punctual and limited their body gestures to the use of hands only.

Teachers' 'language use' and 'tone and volume of voice' varied in their classes. For instances, the ELT teachers mainly resorted to English as the target language and sometime used learners' first language. Their voice was in accordance with the learners' capabilities. In both the hard science and soft science fields, teachers used simple language to ensure learners' comprehension of the subjects and adapted their voice for different purposes: raise attention, retribution, laughter, check of comprehension and so forth. In sum, teachers of all three disciplines heeded this aspect of their teaching.

Lastly, teachers were observed with respect to their 'autonomy' level. It was observed that teachers had some challenges with this feature. Firstly, the majority of teachers irrespective of their discipline were not able to change their instruction according to their learners' needs and interest. This might be because of the large number of learners, teacher burnout, lack of interest by the learners, limited time of instruction and so forth. In addition, teachers regardless of their discipline did not base their activities according to the classroom atmosphere. In other words, they started with a particular plan and even if they noticed learners' disinterest or other factors, they did continue with their initial plan. Teachers also strictly adhered to the syllabus goals. This might have been due to the expectations put on them by the head of departments and other authorizes to cover a particular teaching resource in the designated time of a teaching semester. Although teachers did not have control over the selection of teaching activities to a large extent (in fact they chose certain activities as a supplement to the routine classroom teaching), they were observed to sometimes determine the topics for the teaching subjects or discussion based on their learners' wants. Lastly, teachers did not exercise freedom in the provision of solutions to the problems in the class which might be related to their effort to skip challenges or to stick to the syllabus guidelines. In addition, they were not observed to use particular and effective testing methods such as the use of alternative assessment techniques in order to track their learners' progress. These points in fact held true for all of the observed teachers irrespective of their discipline.

\section{Discussion}

The present study attempted to examine the relationship between different discipline teachers' self-efficacy perceptions and their instructional practice. For this purpose, a mixed-methods research design was used to provide answers to the research questions. The results of quantitative data analysis revealed that on the whole, there was a significant relationship between teachers' self-efficacy and their instructional practice irrespective of their discipline. These findings get support from those of previous studies (e.g., Artino, 2012; Gibson \& Dembo, 1984; Guskey, 1988; Sadeghi \& Khezrlou, 2014, 2016; Woolfolk \& Hoy, 1990). As Richards (2008) rightly notes, teachers' efficacy beliefs allude to and strengthen their classroom instructional practices.

The results of separate correction coefficients in the present study showed that only the soft science and hard science teachers' self-efficacies correlated significantly to their teaching practice, with the ELT teachers not reaching a statistical significance. A clarification of these findings might be that both society and teachers place values upon the teaching of hard science and soft science disciplines. This leads teachers to better cope 
with the difficulties that they encounter at work. Thus, teachers gain a higher sense of social powerfulness to cope with the negative limitations which in turn equips them with the strategies for dealing with barriers to learners' achievement (Richards, 2012). Put another way, they are ensured to have the support to handle the challenges by employing their social capabilities. It also seems that teachers' high perceived selfefficacy empowers them to adapt their endeavours to reduce their problems. Teachers with high self-efficacy guide their attempts internally to alleviate their emotional worries which enhance their effective teaching in the classroom (Bandura, 1997). On the other hand, it was found that the ELT teachers did not develop a link between their efficacy and their actual teaching. They might have been engulfed by the organizational issues such as work overload, support, and isolation which are mainly out of their control. Furthermore, the role ambiguities of not knowing how to compensate for English language learners' knowledge differences, their exposure to different language teaching contexts of high school or institute with distinct teaching styles, learners' different English learning purposes and learners' motivation levels can all be held responsible for decreasing teachers' self-efficacy beliefs and thereby their less satisfying instructional practice. These factors therefore could dismay their beliefs of possessing the required skills and capabilities to lead to learners' achievement and in turn a lower personal selfefficacy (Sadeghi \& Khezrlou, 2014). This finding gives support to Bishop and Berryman's (2009) suggestion that in fact the interaction between teachers and learners in the classroom is the determiner of effective teaching which might result in either positive or negative consequences based on the success of failure of interaction.

These findings, hence, bear significant implications in order to enhance the quality of education in different disciplines. Considering that a limited number of teachers get training as consultants, collaborators, or team teachers at the in-service level (Gable, Young, \& Hendrickson, 1987), their effectiveness may be vulnerable to the role they play and the context and the community in which they work, compared to the education they received (Allinder, 1994). The significance of adapting for teachers' needs, irrespective of the value placed by society of a particular discipline, should be underscored at all levels of pre-service and in-service education. Teachers need to be motivated and equipped with ways of being innovative and creative in their instruction, and to make changes in their instructional routines for the better. Particularly, the practice in differentiated instructional practices which is based on learners' needs, as attested by previous research such as Baecher, Rorimer, and Smith (2012), Kanevsky (2011), Lantolf and Poehner (2010), Okoye-Johnson (2011), has fostered learner achievement.

Teacher educators can observed teachers' classroom practices and provide training on particular ways to help them modify their teaching behaviors and then monitor them in their use of this information (Allinder, 1994). Specific alterations in teaching behavior might consist of different teaching options and decision rules to direct teachers in their application of these alternatives. As use of decision rules and different instructional options influence learners' progress, teachers' efficacy and use of interventions may boost, a hypothesis advocated by prior studies in which teachers' beliefs altered after they noticed the impact of new teaching procedures (Florio-Ruane \& Lensmire, 1990; Guskey, 1988). Another suggestion for teacher education is that teachers need to be taught about the benefits as well as the worth of examining their beliefs, the interactions between their beliefs and actions, and the basis for those beliefs. 
Such introspection would then bring about modifications in teachers' belief systems, either simultaneous with or before changes in knowledge (Nespor, 1987). This illuminates that efficacy is a vital concept for teachers and teacher educators. Teachers 'efficacy and their respective beliefs are related to how teachers perceive their roles, conduct instruction, and interact with students (Khezrlou, 2019a, b, c; Khezrlou, Ellis, \& Sadeghi, 2017).

\section{Conclusion}

Results of this study indicate that the self-efficacy of soft science and hard science teachers was significantly related to their teaching practice; nevertheless, the ELT teachers' efficacy-teaching relation was not statistically significant. Results from the observation and interviews confirmed that teachers particularly ELT teachers encountered several challenges in the classroom which are attributed to different individual and societal issues. On the whole, the findings seem to suggest that teachers need to build and differentiate their teaching practice based on learners' needs and their aims in order to practice teaching satisfactorily. Results of this study are restricted by certain limitations. Firstly, the correlational nature of the results implies that the findings should not be interpreted to imply causation. Secondly, the study used a small sample of teachers which makes it hard to claim their representativeness of teachers in general. Thus, the generalizability of the results to other contexts is limited. However, the rich examination of the results based on the observation and interviews analyses augments the validity of the analysis. Future studies are encouraged to investigate a larger group of participants and their ideas to establish a more rigorous theoretical basis for language teachers' pedagogical knowledge, classroom teaching and their self-efficacy beliefs. It should also be noted that the final objective of teacher education research is to elevate learners' achievement, yet the present study only focused on the teachers. Given that learners also have a crucial role in the teaching and learning process, future research needs to relate teacher efficacy and practice to learners' learning. As an example, examining learners' perceptions about English learning to note if they are congruent with their teachers' can be a worthwhile area of inquiry. It is now widely acknowledged that disagreements between teachers' beliefs and students' beliefs will hamper teachers' work and teacher effectiveness. Another point to mention is that since teacher efficacy is a multifaceted construct which changes across tasks and contexts, it should be studied in different contexts with teachers from diverse backgrounds. Exploring the distinctions among disciplines other that those examined in the present study will also bring about insights into the research on teacher efficacy. Finally, more experimental studies are needed to look into the teachers' long-term teaching practice which would open up horizons on the ways that teachers' efficacy and their practice become challenged and shaped during time.

\section{Acknowledgements}

We would like to appreciate the reviewers of the study for their constructive comments on earlier version of the paper as well as the all the participants of the study.

Authors' contributions

SKK collected and analyzed the data. MHY discussed the results. Both are equally accountable for all aspects of the work and read and approved the final manuscript. 
Availability of data and materials

Please contact the corresponding author for requesting the data.

\section{Competing interests}

The authors declare that they have no competing interests.

Received: 30 August 2019 Accepted: 21 January 2020

Published online: 06 February 2020

\section{References}

Allinder, R. M. (1994). The relationship between efficacy and the instructional practices of special education teachers and consultants. Teacher Education and Special Education, 17(2), 86-95.

Artino, R. A. J. (2012). Academic self-efficacy: From educational theory to instructional practice. Perspectives in Medical Education, 1, 76-85.

Azano, A., Missett, T. C., Callahan, C. M., Oh, S., Brunner, M., Foster, L. H., \& Moon, T. R. (2011). Exploring the relationship between fidelity of implementation and academic achievement in a third grade gifted curriculum: A mixed-methods study. Journal of Advanced Academy, 22(5), 693-719.

Baecher, L., Rorimer, S., \& Smith, L. (2012). Video-mediated teacher collaborative inquiry: Focus on English language learners. The High School Journal, 95(3), 49-61.

Baecher, L., Artigliere, M., Patterson, D. K., \& Spatzer, A. (2012). Differentiated instruction for English language learners as "variations on a theme". Middle School Journal, 43(3), 14-21.

Bandura, A. (1977). Social learning theory. Englewood Cliffs: Prentice-Hall.

Bandura, A. (1989). Social cognitive theory. In R. Vasta (Ed.), Annals of child development, Six theories of child development (Vol. 6, pp. 1-60). Greenwich: JAl Press.

Bandura, A. (1997). Self-efficacy: The exercise of control. New York: W. H. Freeman and Company.

Bishop, R., \& Berryman, M. (2009). The Te Kotahitanga effective teaching profile. Set, 2, 27-33.

Brooks, K., \& Thurston, L. P. (2010). English language learner academic engagement and instructional grouping configurations. American Secondary Education, 39, 45-60.

Burnett, C. (2010). Technology \& literacy in early childhood educational settings: A review of research. Journal of Early Childhood Literacy, 10(3), 247-270.

Burns, R. B. (2000). Introduction to research methods. London: Sage.

Caprara, G. V., Fida, R., Vecchione, M., Del Bove, G., Vecchio, G. M., Barbaranelli, C., \& Bandura, A. (2008). Longitudinal analysis of the role of perceived self-efficacy for self-regulated learning in academic continuance and achievement. Journal of Educational Psychology, 100(3), 525-534.

Caprara, G. V., Vecchione, M., Alessandri, G., Gerbino, M., \& Barbaranelli, C. (2011). The contribution of personality traits and self-efficacy beliefs to academic achievement: A longitudinal study. British Journal of Educational Psychology, 81, 78-96.

Cohen, L., Manion, L., \& Morrison, K. (2011). Research methods in education (7th ed.). Abingdon: Routledge.

Corbin, J., \& Strauss, A. (2008). Basics of qualitative research: Techniques and procedures for developing grounded theory (3rd ed.). Thousand Oaks: Sage Publications, Inc..

Creswell, J. W. (2009). Research design: Qualitative, quantitative, and mixed methods approaches (3rd ed.). Los Angeles: Sage Publications, Inc..

Deci, E. L., \& Ryan, R. M. (1985). Intrinsic motivation and self-determination in human behavior. New York: Plenum Press.

Fang, Z. (1996). A review of research on teacher beliefs and practices. Educational Research, 38, 47-65.

Florio-Ruane, S., \& Lensmire, T. J. (1990). Transforming future teachers' ideas about writing instruction. Curriculum Studies, 22, $277-289$.

Gable, R. A., Young, C. C., \& Hendrickson, J. M. (1987). Content of special education teacher preparation: Are we headed in the right direction? Teacher Education and Special Education, 10, 135-139.

Gibson, S., \& Dembo, M. (1984). Teacher efficacy: A construct validation. Journal of Educational Psychology, 76, 569-592.

Gorand, P., \& Taylor, J. F. (2004). The use of mixed methods across across seven business and management fields. In Justice and sustainability in the global economy: 10th International Federation of Scholarly Associations of Management (IFSAM 2010). Paris: IFSAM.

Graham, S., MaCarthur, C. A., \& Fitzgerald, J. (Eds.). (2007). Solving problems in the teaching of literacy: Best practices in writing instruction. New York: Guilford Press.

Guskey, T. R. (1988). Teacher efficacy, self-concept, and attitudes toward the implementation of instructional innovation. Teaching and Teacher Education, 4, 63-69.

Guskey, T. R., \& Passaro, P. D. (1994). Teacher efficacy a study of construct dimensions. American Educational Research Journal, $31,627-643$.

Halvorsen, A., Lee, V., \& Andrade, F. (2009). A mixed-method study of teachers' attitudes about teaching in urban and lowincome schools. Urban Education, 44(2), 181-224.

Hemphill, F. C., Vanneman, A., \& Rahman, T. (2011). Achievement gaps: How Hispanic and white students in public schools perform in mathematics and reading on the National Assessment of educational Progress. Washington, DC: National Center for education statistics, Institute of Education Sciences, U.S. Dept. of Education.

Hong, E., Greene, M. T., \& Higgins, K. (2006). Instructional practices of teachers in general education classrooms and gifted resource rooms: Development and validation of the instructional practice questionnaire. The Gifted Child Quarterly, 50(2), 91-103.

Kalaja, P., \& Barcelos, A. M. F. (Eds.). (2003). Beliefs about SLA: New research approaches. Dordrecht: Kluwer.

Kanevsky, L. (2011). Deferential differentiation: What types of differentiation do students want? The Gifted Child Quarterly, 55(4), 279-299.

Khezrlou, S. (2019a). Effects of timing and availability of isolated FFI on learners' written accuracy and fluency through task repetition. The Language Learning Journal. https://doi.org/10.1080/09571736.2019.1656765. 
Khezrlou, S. (2019b). Task repetition and corrective feedback: The role of feedback types and structure saliency. English Teaching and Learning, 43(2), 213-233.

Khezrlou, S. (2019c). Form-focused instruction in CALL: What do learners think? RELC, 50(2), 235-251.

Khezrlou, S., Ellis, R., \& Sadeghi, K. (2017). Effects of computer-assisted glosses on EFL learners' vocabulary acquisition and reading comprehension in three learning conditions. System, 65, 104-116.

Lantolf, J. P., \& Poehner, M. E. (2010). Dynamic assessment in the classroom: Vygotskian praxis for second language development. Language Teaching Research, 15(1), 11-33.

Lawson, T., Cakmak, M., Gunduz, M., \& Busher, H. (2015). Research on teaching practicum: A systematic review. European Journal of Teacher Education, 38(3), 392-407.

McNeill, P., \& Chapman, S. (2005). Research methods. London: Routledge.

Menter, I., Elliot, D., Hulme, M., Lewin, J., \& Lowden, K. (2011). A guide to practitioner research in education. London: Sage.

Merriam, S. B. (1998). Qualitative research and case study applications in education. San Francisco: Jossey-Bass.

Morse, J. M., \& Neihaus, L. (2009). Mixed method design: Principles and procedures. Walnut Creek: Left Coast Press Inc.

Nespor, J. (1987). The role of beliefs in the practice of teaching. Curriculum Studies, 19, 317-328.

NevJrez-La Torre, A. A. (2011). Transiency in urban schools: Challenges and opportunities in education ELLs with a migrant background. Education and Urban Society, 44(1), 3-34.

Noe, R. A., \& Wilk, S. L. (1993). Investigation of the factors that influence employee's participation in development activities. Journal of Applied Psychology, 78, 291-302.

O'Conner, R., Abedi, J., \& Tung, S. (2012). A descriptive analysis of enrollment and achievement among limited English proficient students in New Jersey (issues \& answers, REL 2012-no. 108).

Okoye-Johnson, O. (2011). Intangible heritage of standard English learners: The "invisible" subgroup in the United States of America? Implications for closing the achievement gap. United Kingdom: SAGE Open, 1(2), 1-7. https://doi.org/10.1177/ 2158244011408441

Orosco, M. J., \& O'Connor, R. (2014). Culturally responsive instruction for English language learners with learning disabilities. Journal of Learning Disabilities, 47(6), 1-17.

Pandya, C., Batalova, J., \& McHugh, M. (2011). Limited English proficient individuals in the United States: Number, share, growth, and linguistic diversity. Washington, DC: Migration Policy Institute.

Reis, S. M., McCoach, D. B., Little, C. A., Muller, L. M., \& Kaniskan, R. B. (2011). The effects of differentiated instruction and enrichment pedagogy on reading achievement in elementary schools. American Educational Research Journal, 48(2), 462-501.

Richards, J. C. (2008). Second language teacher education today. RELC Journal, 39(2), 158-177.

Richards, J. C. (2011). Classroom observation in teaching practice. In J. C. Richards \& T. S. C. Farrell (Eds.), Practice teaching: A reflective approach (pp. 90-106). Cambridge: Cambridge University Press.

Robinson, V. M. J., \& Lai, M. K. (2006). Practitioner research for educators: A guide to improving classrooms and schools. Thousand Oaks: Corwin Press.

Runhaar, P., Sanders, K., \& Yang, H. (2010). Stimulating teachers' reflection and feedback asking: An interplay of self-efficacy, learning goal orientation, and transformational leadership. Teaching and Teacher Education, 26(5), 1154-1161.

Sadeghi, K., \& Khezrlou, S. (2014). Burnout among English language teachers in Iran: Do socio-demographic characteristics matter? Procedia- Social and Behavioural Sciences, 98, 1590-1598.

Sadeghi, K., \& Khezrlou, S. (2016). The experience of burnout among English language teachers in Iran: Self and other determinants. Teacher Development, 20(5), 1-17.

Sarantakos, S. (2005). Social research. New York: Palgrave Mac-Millan.

Schunk, D. H. (1991). Self-efficacy and academic motivation. Educational Psychologist, 26, 207-231.

Schunk, D. H., \& Meece, J. L. (2006). Self-efficacy development in adolescence. In F. Pajares \& T. Urdan (Eds.), Self-efficacy beliefs of adolescents (pp. 71-96). Greenwich: Information Age Publishing.

Tschannen-Moran, M., Woolfolk-Hoy, A., \& Hoy, W. K. (1998). Teacher efficacy: Its meaning and measure. Review of Educational Research, 68(2), 202-248.

VanTassel-Baska, J. (2012). Analyzing differentiation in the classroom. Gifted Child Today, 35(1), 43-48.

Vygotsky, L. S. (1978). Mind in society: The development of higher psychological processes. Cambridge: Harvard University Press.

Wilson, T. (2012). Soft sciences doesn't deserve the snobbery. The Los Angeles times. Retrieved January 10, 2018, from http:// www.latimes.com

Woolfolk, A. E., \& Hoy, W. K. (1990). Prospective teachers' sense of efficacy and beliefs about control. Journal of Educational Psychology, 8, 812-891.

\section{Publisher's Note}

Springer Nature remains neutral with regard to jurisdictional claims in published maps and institutional affiliations. 